\title{
RESEARCH ON EVOLUTION OF COLLABORATION MECHANISM OF STAKEHOLDERS IN MINING ENTERPRISES' IMPLEMENTATION OF SOCIAL RESPONSIBILITY
}

\author{
XingXin NiE ${ }^{1, *}$, JingJing ZhAng ${ }^{2}$ And Luhan YANG ${ }^{2}$
}

\begin{abstract}
Multiple stakeholders are involved when mining enterprises assume their social responsibility, so a tripartite game pattern among local government, mining enterprises and local community is formed after supervision is introduced. By combining evolutionary game model with system dynamics for simulation analysis, this paper studies the dynamic game process among the three parties and we find out that: (1) local government, mining enterprises and local community will eventually reach a stable equilibrium state (supervision, participation, performance), and it will simplify the evolutionary path of the stable equilibrium state when local government chooses supervision at the early stage; (2) local government plays a leading role in supervision, and the strategy choices of mining enterprises and local community depend on local government's strategy and the relationship between the size of exogenous; (3) the formation of the eventual stabilization strategy is decided by the joint action of multiple variables, although every single variable will affect the strategy choice of all parties, so local government should deal with the relationship between various stakeholders properly.
\end{abstract}

Mathematics Subject Classification. 91A22, 74H55, 70F07.

Received June 25, 2019. Accepted March 8, 2020.

\section{INTRODUCTION}

Historically, the mining industry is one of the oldest documented kinds of human activity [5]. Mankind has benefited from acquiring the mineral resources, and the extraction of mineral resources in a global scale continues to increase today. However, mineral resources are limited. In order to ensure the further existence of life on earth and the better development of the economy, a sustainable development strategy should be emphasized and adopted. The strategy is, in any case, an ongoing process, but not a temporary undertaking $[16,65]$. About the sustainable development [22,62] of mining industry, as a common principle, has already reached a consensus in the global mining industry. Corporate social responsibility (CSR) is a responsibility system based on the sustainable development [63]. It refers to the responsibility of an enterprise for its stakeholders $[13,28,49]$ during the business operation, which means that enterprises should not only consider their own financial and operational conditions, but also fulfill their responsibilities to the environment and society. And it is the result of interaction between enterprises, government, and society [34,73]. There are two situations when the

Keywords. Mining enterprise, social responsibility, game theory, system dynamics.

1 School of Resources Engineering, Xi'an University of Architecture and Technology, 710055 Xi'an, Shaanxi, P.R. China.

2 School of Management, Xi'an University of Architecture and Technology, 710055 Xi'an, Shaanxi, P.R. China.

* Corresponding author: niexingxin@126.com 
corporate assumes the social responsibility, namely fulfilling the responsibility and not fulfilling the responsibility. Thinking of corporate social responsibility as a system, we introduce the variable $A^{*}$ to indicate the degree of the willingness of the company to perform its duties. When the company fulfill its responsibilities, the variable $A^{*}$ is 1 . When the enterprise chooses not to perform the responsibility, the variable $A^{*}$ is 0 . And the closer the variable $A^{*}$ is to 1 , the greater the willingness of the company to fulfill its responsibilities is; the closer the variable $A^{*}$ is to 0 , the smaller the willingness of the company to perform its duties is. Over the past decade, corporate social responsibility has become one of the most important concerns in the global mining industry. Now, there is a general lack of corporate social responsibility in Chinese mining industry, and the weak sense of responsibility $[12,40,57]$ in these mining enterprises has seriously hindered the healthy development of Chinese mines.

About the evolutionary game theory, it can be applied to analyze the fulfillment of social responsibility. Chen [3] has made in-depth analysis the mechanism of evolution of the social responsibility hierarchy by using replication dynamic model from the perspective of a multi-population evolutionary game. Li et al. [27] established evolutionary game model on social responsibility between food manufactures and third-party e-commerce platform and set up some related parameters and variables hypothesis based on some actual conditions. Wang and $\mathrm{Li}[60]$ set up the selection game model of air service provider based on corporate social responsibility, and the relationship between the performance level of corporate social responsibility and the selection of air service provider was analyzed. Zhang et al. [71] analyzed the complete information and the incomplete information of the "rent-seeking behavior" of multinational corporations by constructing the dynamic game model of multinational corporations' social responsibility practice and host government supervision. Zhang et al. [70] established the three game models to explore how to make coal enterprises fulfill social responsibility conscientiously. Fang et al. [6] analyzed a public-private partnership cooperation scheme based on evolutionary game theory. Zuo and Zhang [74] applied evolutionary game theory model to examine electricity producers strategies in this scheme context. Sohrabi and Azgomi [56] represented an evolutionary game theory-based method to materialized view selection in the data warehouse.

Once mining enterprises fulfill their social responsibility, multiple stakeholders [11,43,64] will be involved, such as central government, local government, mining enterprises, employees of mining enterprises and local community, etc., and these independent and different interest groups may present a complex relationship. Meanwhile, the inconsistency of respective interests $[9,23,41]$ leads to conflicts and has a negative impact on the fulfillment of social responsibility. In this paper, we select local government, local community and mining enterprises as the main stakeholders to analyze their complex interest relationships, on condition that mining enterprises fulfill the social responsibility. The evolutionary game theory is proposed to construct the evolutionary game model among the main stakeholders $[24,67,68]$. And the model reveals the motivation of stakeholders' decision-making and obtains their strategy choices to achieve a balanced and stable state of the system $[10,33,39,55]$, so as to put forward the corresponding countermeasures and suggestions for mining enterprises to effectively fulfill their social responsibility.

\section{Game AnAlysis AMONG MAJOR PARTiCipants}

Stakeholder theory [1] refers to people who can influence the achievement of an organization's goals or can be influenced by the organization's achievement of the target process. According to the stakeholder theory, it can be determined that the main stakeholders when mining enterprises fulfill their social responsibility are local government, local community and mining enterprises. They will perform different game behaviors during the game process and dynamically adjust their strategy choices through the respective game focus $[8,15,42]$.

\subsection{Game between local government and mining enterprises}

Among the stakeholders, local government has a huge impact on mining enterprises, as the acquisition of mineral rights $[4,17,69]$ in China depends on local government. As the participant and implementer of mineral resources management, local government on behalf of the state manages mineral resources and standardizes the order of mineral resources exploitation $[2,7,14,45]$. Local government and mining enterprises have both 
contradictions and cooperation in the mineral resources' development. On the one hand, mining enterprises, a profit-making organization, seek to maximize their own interests $[25,30,38]$, but ecological compensation for mineral resources development will increase their cost. On the other hand, local government representing our country to supervise and manage mining industry maintains the order of mineral resources development, and monitors and punishes mining enterprises when these enterprises destroy the ecological environment.

\subsection{Game between local community and mining enterprises}

Mining enterprises' activities are closely related to many factors in local community, which inevitably links mine enterprises with local community to form a complex relationship of responsibility and interests. And mining enterprises can provide employment opportunities, create tax payoff and promote economic development for local community. But the production and operation activities of mining enterprises will also pollute the ecological environment of local community and endanger its environmental safety $[31,59,61]$. As two different stakeholders, mining enterprises and local community strive for their best interests [26]. Therefore, apart from local government, local community should actively participate in the supervision on mining enterprises.

\subsection{Game between local government and local community}

Due to the unreasonable payoff distribution system $[36,44,72]$ of mineral resources and the inadequate supervision of local government, mining enterprises fail to fulfill their social responsibilities, which will bring local community some bad effects, such as environmental pollution, ecological damage $[19,35,58]$, low level of resource utilization and losses of social welfare. Therefore, local government should improve the distribution system of mineral resources development payoff and strengthen the supervision and punishment.

To sum up, in the social responsibility of mining enterprises, local government can choose strategies set as \{encouraging local community participation, supervising mining enterprises; encouraging local community participation, not supervising mining enterprises\}; local community can choose strategies set as \{participating in supervision; not participating in supervision\}; mining enterprises can choose strategies set as \{undertaking; not undertaking $\}$. In this paper, we select $\alpha, \beta, \gamma$ to respectively express the probability of local government's supervision, local community's participation in supervision, and mining enterprises' fulfillment social responsibility. Among them, $0 \leq \alpha, \beta, \gamma \leq 1$.

\section{Construction of supervision evolutionary game model}

The evolutionary game theory is the extended version of the classic game theory in which the concept of evolving populations has been explored. And the theory holds that the participants in the system are randomly combined. Most participants will try to learn and imitate according to the different rules, however, a small number of participants' strategies will mutate, and the accumulation of different choices can constitute the evolution process of economic subjects [6]. The theory suitable to analyze the dynamic game process of multiple players is a theoretical analysis method which combines game equilibrium with dynamic selection mechanism $[46,53]$.

\subsection{Determination of main parameters and payment matrix}

The main parameters $[21,47]$ involved in evolutionary game can be determined by the analysis of game focus.

(1) Regarding the main exogenous variables involved in the local government: (1) the total income $R_{1}$ is the income earned by the mining enterprises during the mining process. In order to maximize their own interests, mining enterprises may adopt non-compliant mining methods, technologies, materials and equipment, which may violate the principle of the enterprise; (2) fine $K$ is a fine imposed by the local government on irregular behavior of mining enterprises. If there is a company's failure to perform social responsibility without fines, then more and more enterprises will not mine normatively, which will cause great damages to the social economy and the environment; (3) $M_{1}$ is compensation for damage to the local community. When the mining 
TABLE 1. Tripartite game payoff matrix when local government supervises $(\alpha)$.

\begin{tabular}{llll}
\hline \hline & & & Mining enterprises \\
\cline { 2 - 3 } & & Fulfilling $(\gamma)$ & Not fulfilling $(1-\gamma)$ \\
\hline Local & Participating $\beta$ & $\left(R_{1}-C_{1} ; R_{2}-C_{2}+P_{2} ; R_{3}-C_{3}\right)$ & $\left(R_{1}-C_{1}+K ; R_{2}-C_{2}-F_{2}+M_{2} ; R_{3}+K-F_{3}-M_{2}\right)$ \\
Community & Not participating $1-\beta$ & $\left(R_{1}-C_{1} ; P_{2} ; R_{3}-C_{3}\right)$ & $\left(R_{1}-C_{1}+K ; 0 ; R_{3}-K\right)$ \\
\hline
\end{tabular}

TABLE 2. Tripartite game payoff matrix when local government doesn't supervise $(1-\alpha)$.

\begin{tabular}{|c|c|c|c|}
\hline & & \multicolumn{2}{|c|}{ Mining enterprises } \\
\hline & & Fulfilling $(\gamma)$ & Not fulfilling $(1-\gamma)$ \\
\hline $\begin{array}{l}\text { Local } \\
\text { Community }\end{array}$ & $\begin{array}{l}\text { Participating } \beta \\
\text { Not participating } 1-\beta\end{array}$ & $\begin{array}{l}\left(R_{1} ; R_{2}-C_{2}+P_{2} ; R_{3}-C_{3}\right) \\
\left(R_{1} ; P_{2} ; R_{3}-C_{3}\right)\end{array}$ & $\begin{array}{l}\left(R_{1}-M_{1} ; R_{2}-C_{2}-F_{2}+M_{1} ; R_{3}+T-F_{3}\right) \\
\left(R_{1} ; 0 ; R_{3}+T\right)\end{array}$ \\
\hline
\end{tabular}

Notes. The first function item in the table represents local government's payoff, the second function item represents local community's payoff, and the third function item represents mining enterprises' payoff.

enterprises fail to fulfill their social responsibilities and the local government does not supervise, the water, soil and air of the local community may be polluted. Under this situation, cash crops may reduce production or even die, so there will be the compensation for the local community; (4) the cost of supervision $C_{1}$ refers to the resources spent by the supervisory body (local government department) in the implementation of the supervision process. The resources can be manpower, material resources, time, etc.

(2) Regarding the main exogenous variables involved in the local community: (1) $R_{2}$ is the fixed income. When the local community actively participates in the supervision, it will gain income, and its participation in the supervision is not unpaid; (2) $P_{2}$ is the indirect benefit. When the mining enterprise is in the production process, it will offer the employment opportunities, tax revenues and drive the development of the local economy; (3) the supervising cost of mining enterprises $C_{2}$ is the loss of human, material and financial resources incurred by the community, when it participates in the supervision of mining enterprises; (4) $F$ is the economic and ecological losses. Enterprises' non-responsible behavior will bring harmful influences to local community. These harmful factors, such as noise, dust, radiation and mine waste water, are bad for the community environment and the health of residents; (5) $M_{2}$ is the compensation from the local government, when the enterprises do not fulfill their responsibility.

(3) Regarding the main exogenous variables $[20,29,52]$ involved in mining enterprises: (1) the fixed income $R_{3}$ is the income obtained by the mining enterprises in the mining activities; (2) the $\operatorname{cost} C_{3}$ is the capital invested the cost of purchasing machinery and equipment and the cost of hiring staff in the mining process; (3) $K$ is the fine of the non-performance of the enterprise; (4) $F_{3}$ is the loss caused by the contradiction between the mining enterprise and the local residents The mining activity of the enterprise will bring pollution to local residents, which will cause dissatisfaction of residents. Once the contradiction occurs it will in turn affect the normal production activities of the enterprise; (5) $T$ is the additional income. If the government does not impose fines on the enterprise when it does not fulfill its social responsibility the enterprise will obtain additional income.

On the basis of the principle of maximization of interests [37], we can list the tripartite game payoff matrix in the case of local government's supervision and no regulation for mining enterprises. The results are shown in Tables 1 and 2 .

\subsection{Determination of income function and dynamic equation}

We use $U_{i j}$ to represent the payoff when the $i$ th stakeholder chooses strategy $j$, in the paper, $i=g, c, s$ which represent local government, local community and mining enterprises respectively, and $j=1,2$ which represent 
the first and second strategies of the stakeholder's strategies. For example, $U_{g 1}$ indicates the revenue of local government when it supervises mining enterprises, $U_{g 2}$ indicates the payoff of local government when it does not supervise mining enterprises.

According to the payoff matrix [32], expected payoff function can be listed when local government supervises the mining enterprises:

$$
\begin{aligned}
U_{g 1} & =\beta \gamma\left(R_{1}-C_{1}\right)+\beta(1-\gamma)\left(R_{1}-C_{1}+K\right)+(1-\beta) \gamma\left(R_{1}-C_{1}\right)+(1-\beta)(1-\gamma)\left(R_{1}-C_{1}+K\right) \\
& =R_{1}-C_{1}+(1-\gamma) K .
\end{aligned}
$$

Expected payoff function when local government does not supervise mining enterprises:

$$
\begin{aligned}
U_{g 2} & =\beta \gamma R_{1}+\beta(1-\gamma)\left(R_{1}-M_{1}\right)+(1-\beta) \gamma R_{1}+(1-\beta)(1-\gamma) R_{1} \\
& =R_{1}+\beta \gamma M_{1}-\beta M_{1} .
\end{aligned}
$$

Average expected payoff function of local government:

$$
\bar{U}_{g}=\alpha U_{g 1}+(1-\alpha) U_{g 2} .
$$

According to formulas (3.1) and (3.2), the replicated dynamic equation of local government's supervision over mining enterprises can be obtained:

$$
\frac{\mathrm{d} \alpha}{\mathrm{d} t}=\alpha\left(U_{g 1}-\bar{U}_{g}\right)=\alpha(1-\alpha)\left(U_{g 1}-U_{g 2}\right)=\alpha(1-\alpha)\left[(1-\gamma) K-C_{1}+(1-\gamma) \beta M_{1}\right] .
$$

Similarly, expected payoff function when local community chooses to participate in supervision:

$$
\begin{aligned}
U_{c 1}=\alpha & \gamma\left(R_{2}+P_{2}-C_{2}\right)+\alpha(1-\gamma)\left(R_{2}-C_{2}-F_{2}+M_{2}\right)+(1-\alpha) \gamma\left(R_{2}+P_{2}-C_{2}\right) \\
& +(1-\alpha)(1-\gamma)\left(R_{2}-C_{2}-F_{2}+M_{1}\right) \\
= & R_{2}-C_{2}+\gamma P_{2}-F_{2}(1-\gamma)+M_{1}(1-\alpha)(1-\gamma)+\alpha(1-\gamma) M_{2} .
\end{aligned}
$$

Expected payoff function when local community doesn't participate in supervision:

$$
U_{\mathrm{c} 2}=\alpha \gamma P_{2}+(1-\alpha) \gamma P_{2}=P_{2}
$$

The replicated dynamic equation of local community's participation in supervision:

$$
\begin{aligned}
\frac{\mathrm{d} \beta}{\mathrm{d} t} & =\beta(1-\beta)\left(U_{c 1}-U_{c 2}\right) \\
& =\beta(1-\beta)\left[R_{2}-C_{2}-(1-\gamma)\left(P_{2}+F_{2}\right)+M_{1}(1-\alpha)(1-\gamma)+\alpha(1-\gamma) M_{2}\right] .
\end{aligned}
$$

Expected payoff function when mining enterprises fulfill their responsibility:

$$
\begin{aligned}
U_{s 1}= & \alpha \beta\left(R_{3}-C_{3}\right)+\alpha(1-\beta)\left(R_{3}-C_{3}\right)+(1-\alpha) \beta\left(R_{3}-C_{3}\right) \\
& +(1-\alpha)(1-\beta)\left(R_{3}-C_{3}\right) \\
= & R_{3}-C_{3} .
\end{aligned}
$$

Expected payoff function when mining enterprises don't fulfill their responsibility:

$$
\begin{aligned}
U_{s 2}= & \alpha \beta\left(R_{3}-K-F_{3}-M_{2}\right)+\alpha(1-\beta)\left(R_{3}-K\right)+(1-\alpha) \beta\left(R_{3}+T-F_{3}\right) \\
& +(1-\alpha)(1-\beta)\left(R_{3}+T\right) \\
= & R_{3}+(1-\alpha) T-\alpha K-\beta F_{3}-\alpha \beta M_{2} .
\end{aligned}
$$


The replicated dynamic equation of mining enterprises' fulfillment of their responsibility:

$$
\frac{\mathrm{d} \gamma}{\mathrm{d} t}=\gamma(1-\gamma)\left(U_{s 1}-U_{s 2}\right)=\gamma(1-\gamma)\left[\alpha K+\beta F_{3}+\alpha \beta M_{2}-C_{3}-(1-\alpha) T\right]
$$

If mining enterprises fulfill their social responsibility, the replicated dynamic equations of local government, local community and mining enterprises will involve the payoff of different strategy combinations and the proportion distribution $[48,50]$ of different strategies, so that the related parameters are numerous, which makes it impossible to obtain an analysis by analyzing Jacobian matrix to judge the stability of eigenvalues [54]. In order to better describe the equilibrium state of co-evolution among these three parties, the paper establishes a three-party evolutionary game model through system dynamics simulation tools, and studies the strategic stability and the changes in expected payoff with changing relevant parameters, so as to determine the most relevant factors affecting the performance of social responsibility of mining enterprises.

\subsection{Evolutionary game model based on SD}

In group evolutionary game, individuals in a group try to describe their own learning evolutionary mechanism by replication dynamics [18]. Imitating and comparing their own benefits with other individuals in the same population, they attempt to adjust their strategic choices. We'll use Vensim a software to construct a system dynamics model based on evolutionary game analysis.

(1) The main variables involved in the SD model are all listed in 2.2.

(2) On the basis of causal loop diagram, we further distinguish the nature of variables and draw stock flow diagram. According to formulas (3.1)-(3.9), the relationship and function of variables in the model are written, in which $\alpha, \beta, \gamma$ represent horizontal variables. Three rate variables are local government supervision change rate $\frac{\mathrm{d} \alpha}{\mathrm{d} t}$, local community participation change rate $\frac{\mathrm{d} \beta}{\mathrm{d} t}$ and mining enterprise fulfillment change rate $\frac{\mathrm{d} \gamma}{\mathrm{d} t} . R_{1}, C_{1}, M_{1}, K, R_{2}, C_{2}, M_{2}, P_{2}, F_{2}, R_{3}, C_{3}, F_{3}$ and $T$ are exogenous variables; $U_{g 1}, U_{g 2}, U_{\mathrm{c} 1}, U_{c 2}, U_{s 1}, U_{s 2}$ represent six intermediate variables.

(3) According to formulas (3.1)-(3.9), the relationship and equation of variables in the model are written, in which $\frac{\mathrm{d} \alpha}{\mathrm{d} t}, \frac{\mathrm{d} \beta}{\mathrm{d} t}$ and $\frac{\mathrm{d} \gamma}{\mathrm{d} t}$ represent local government supervision change rate, local community participation change rate and mining enterprise fulfillment change rate respectively. The functional relationship between stock and rate variables, intermediate variables and stock, intermediate variables and exogenous variables can be clearly described by the nine equations.

(4) In this study, we assume that all exogenous variables are positive, and ensure that the strategic returns of each strategy are positive. Therefore, we assign the following initial values to exogenous variables.

$R_{1}=50, C_{1}=15, M_{1}=14, K=20, R_{2}=11, C_{2}=4, M_{2}=7, P_{2}=9, F_{2}=5, R_{3}=65, C_{3}=25$, $F_{3}=17, T=13$. Finally, the SD simulation model of the three-party evolutionary game system shown in Figure 1 is formed.

\section{Simulation Analysis}

In this chapter we will analyze the strategic choices of local governments local communities and mining companies in the context of pure strategies and the introduction of exogenous variables.

\subsection{Simulating analysis of pure strategy game}

Although we can know that there will inevitably be an evolutionary equilibrium among local government, local community and mining enterprises through the equilibrium analysis of evolutionary game model, it is difficult to identify the reasons and processes for achieving the equilibrium, whether the equilibrium is unique or stable, and even if all parties have reached the equilibrium in a certain situation, the equilibrium may also be broken due to internal and external disequilibrium. Hence, depending on the hypothetical value of each parameter and the equation between variables, we use SD and Vensim to simulate the dynamic game process 


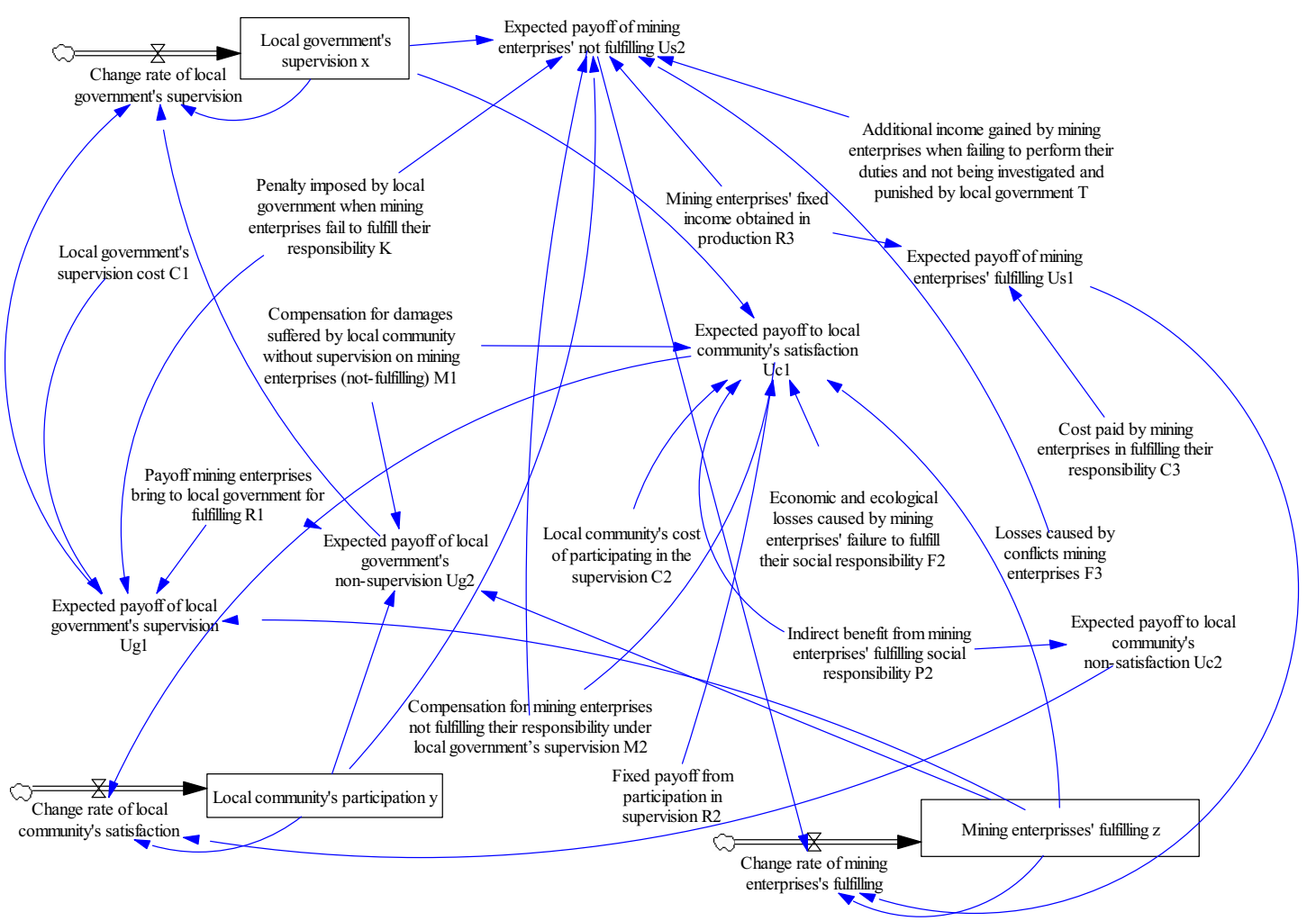

FiguRE 1. SD simulation model of evolutionary game system among local government, local community and mining enterprises.

among the three parties. We set the simulation period to be 72 , INITIAL TIME $=0$, FINAL TIME $=72$, TIME $\mathrm{STEP}=0.5$, and take the strategic probability of the three stakeholders as the main measurement index, so as to analyze the related influencing factors when mining enterprises fulfill their social responsibility.

In the process of mining enterprises' fulfilling their social responsibility, if the initial values of the three parties are all of pure strategy, the participating entities will have two kinds of strategy choices: 0 and 1 , namely, the following eight strategy combinations $(0,0,0),(1,0,0),(1,1,0),(0,1,0),(0,1,1),(1,1,1),(1,0,1)$, $(0,0,1)$. Software simulation shows that no party in the system is willing to change the current state and break the balance when the initial state of three parties is of pure strategy. However, once the three parties make the minor changes, the equilibrium will be broken. To grasp the evolutionary state of the three parties, we make their changes a little and take strategy $(0,0,0)$ as an example, the initial value for simulation is $(0.01,0.01,0.01)$. Similarly, for strategy $(1,1,1)$, the initial value is $(0.99,0.99,0.99)$, and then we will analyze two scenarios of local government's initial strategy.

Scenario 1: Local government's initial strategy has no supervision, which means that local government has minimal willingness to supervise at first.

In this case, local government, local community and mining enterprises have four initial strategic combinations, and the strategic evolution paths of the three parties are shown in Figure 2-5.

If mining enterprises initially adopt not-fulfilling strategy (as shown in Fig. 2 or Fig. 4), the supervision willingness of local government will increase rapidly, and then the possibility of mining enterprises' initiative fulfilling will rise sharply until its stability is achieved. At the same time, the government also tends to the supervise until the stability comes. Comparing Figure 2 with Figure 4, we find that whether local community 


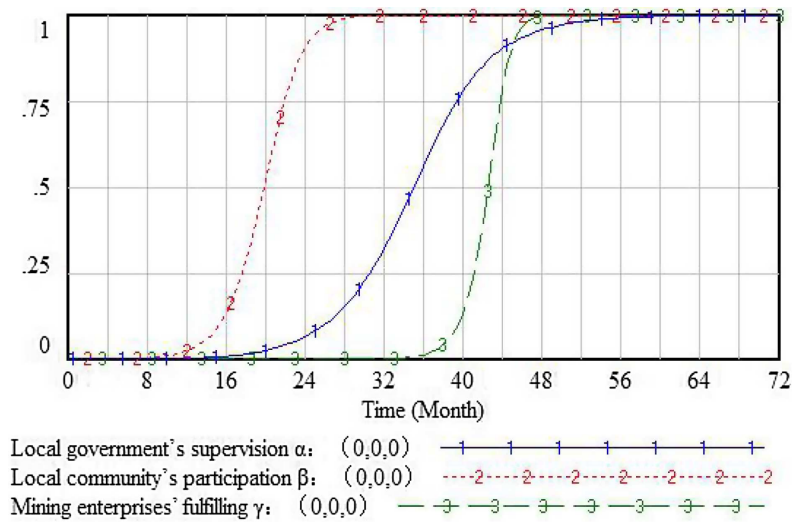

Figure 2. Strategic evolution path when the initial strategy is $(0,0,0)$.

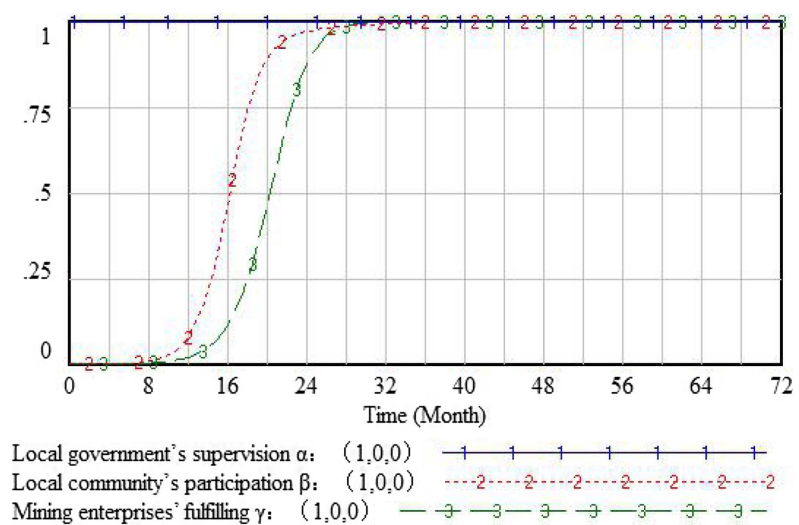

Figure 3. Strategic evolution path when the initial strategy is $(0,0,1)$.

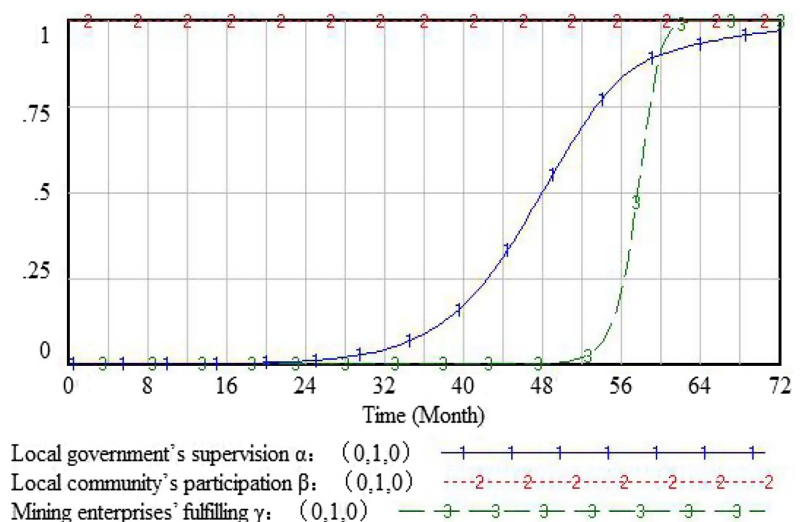

FIGURE 4. Strategic evolution path when the initial strategy is $(0,1,0)$. 


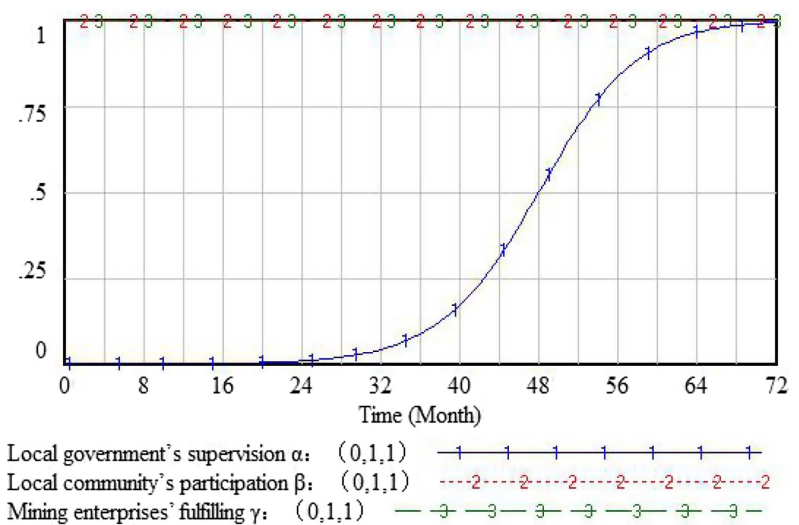

FIGURE 5. Strategic evolution path when the initial strategy is $(0,1,1)$.

initially adopts participation or not, their final strategy evolution path is participation. When mining enterprises initially adopt the fulfilling strategy (as shown in Figs. 3 and 5), local government won't supervise originally, but the ultimate strategy evolution path is supervision, and the ultimate strategy of mining enterprises is actively fulfilling. Contrasting Figure 3 with Figure 5, we can see that the final strategy evolution path is participation whether local community adopts participation strategies or not firstly.

Conclusion 1: In the case of the initial poor willingness of local governments, local governments will eventually choose strategy 1 choosing regulation. Whether it changes from 0 or 1 , local community will ultimately choose strategy 1 participating in supervision, and mining enterprises will ultimately choose strategy 1 which is to fulfill their responsibility actively. In the end, the three parties will reach a balance at $(1,1,1)$, namely (local government's supervising, local community's participating, mine enterprises' actively fulfilling).

Scenario 2: Local government's initial strategy is to supervision, that is, local government has strong willingness to supervise primarily.

In this case, local government, local community and mining enterprises also have four initial strategic combinations and the evolutionary paths of the strategy of the three parties are shown in Figures 6-9. When mining enterprises initially adopt not-fulfilling strategy (as shown in Figs. 6 and 8), local government will have been adopting supervision strategy. As the active fulfilling willingness of mining enterprises has risen straightly, the stability will finally achieve at the active fulfilling strategy. At the same time, local government has also approached to the supervision strategy until stability. Comparing Figure 6 with Figure 8, when local government chooses to supervise at the beginning, whether local community initially adopts participating strategy or not, its final strategy evolution path is participating. When mining enterprises adopt the active fulfilling strategy initially (as shown in Figs. 7 and 9), they will be always adopting the fulfilling strategy, while local government achieves stability at the supervision state. Figures 7 and 9 also confirm that in the case of local government's initial supervision, the ultimate strategy evolution path is participation whether local community initially adopts participating strategies or not.

Conclusion 2: In the case of local government's strong willingness of supervision firstly, the three parties will eventually achieve a balance at $(1,1,1)$, namely (local government's supervising, local community's participating, mine enterprises' actively fulfilling).

\subsection{Simulation analysis of exogenous variables on stakeholder's strategy choice}

The software analysis shows that the equilibrium value of each strategy combination depends on the value of exogenous variables. To further explore the sensitivity of the strategy choice of each game party to exogenous variables, this Section simulates the influence of the initial value of each exogenous variable on the choice of 


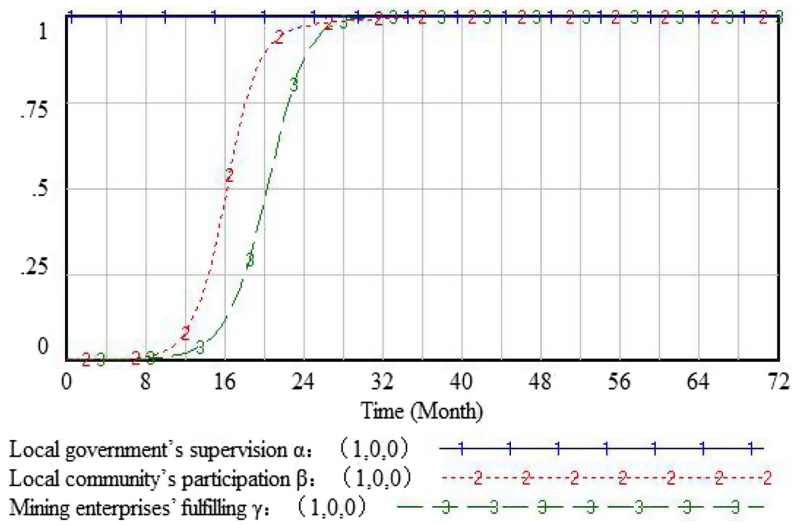

Figure 6. Policy evolution path when the initial strategy is $(1,0,0)$.

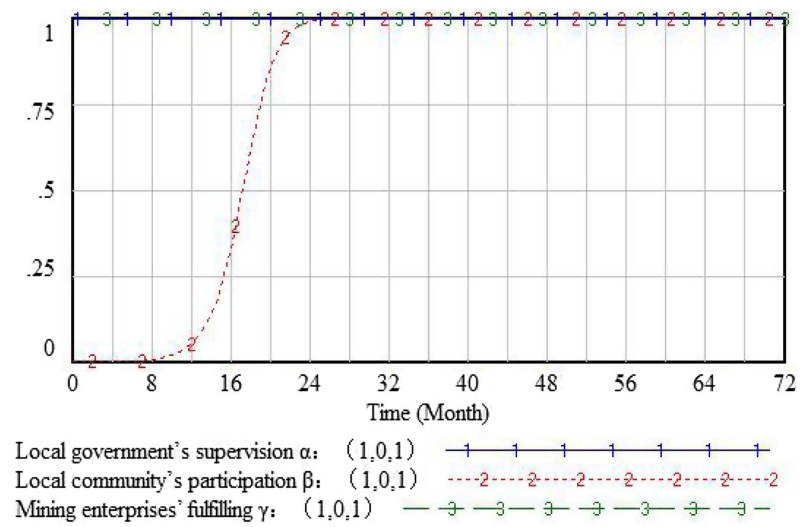

FiguRE 7. Strategic evolution path when the initial strategy is $(1,0,1)$.

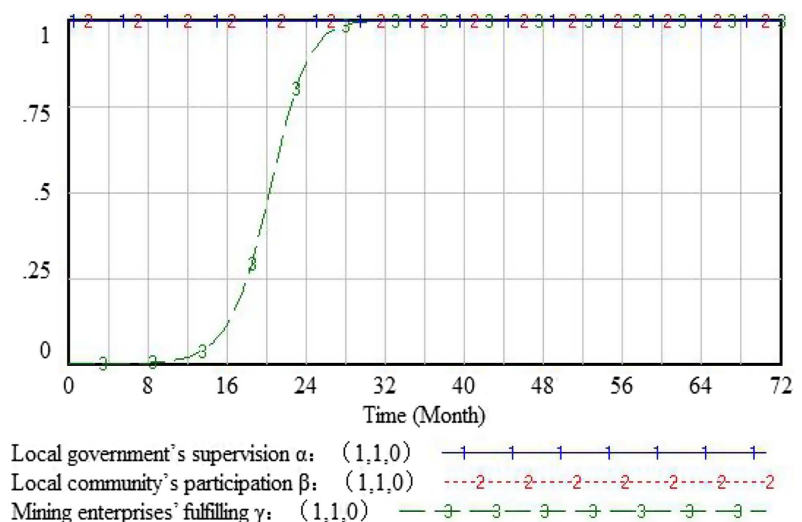

FiguRE 8. Strategic evolution path when the initial strategy is $(1,1,0)$. 


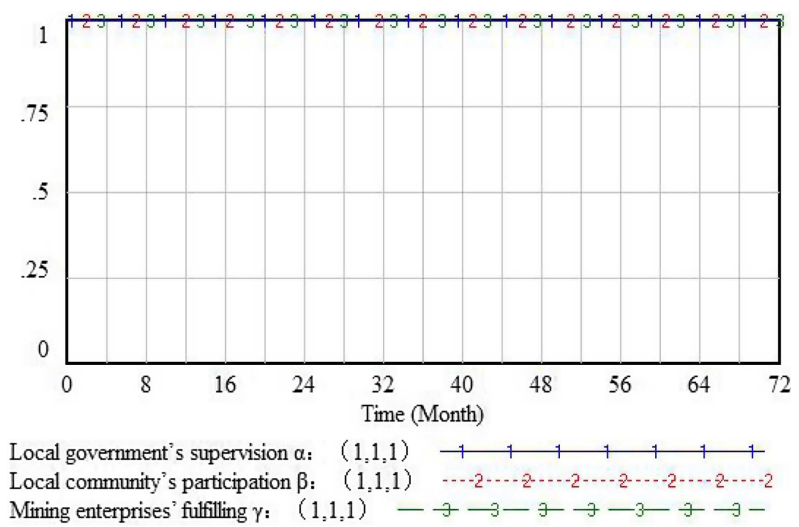

FIGURE 9. Strategic evolution path when the initial strategy is $(1,1,1)$.

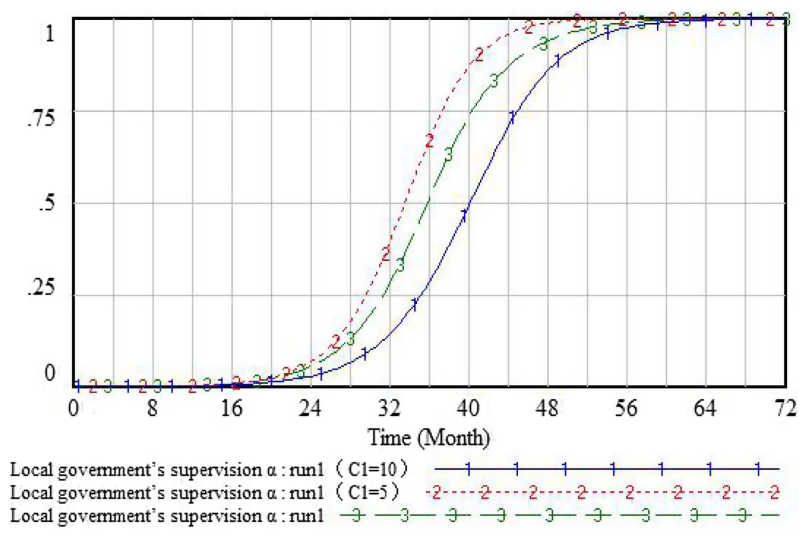

FIGURE 10. $C_{1}$ 's influence on local government's strategy choice.

strategy by changing the initial value of each exogenous variable, so as to find out the key factors affecting the evolution of each party. Since the final evolutionary stable states of different strategy combinations are consistent, we regard the strategy combination $(0,0,0)$ as the analysis object.

(1) The influencing factors on local government's strategy choice.

Even if strategy combination $(0,0,0)$ is selected as the simulation object, to analyze the influencing process of exogenous variables on local government's strategy choice, it can be assumed that the initial strategy of local government is not-supervising, and mutation evolution [51] is carried out with the probability of 0.01 . Through dynamic simulation, we can see that among all the exogenous variables, local government's penalty $K$ and supervision $\operatorname{cost} C_{1}$ will have an impact on local government's strategy choice.

It is clear to see in Figure 10 that the speed of the strategy choice tending to supervision slows down gradually with local government's increasing supervision cost. Which means, the higher the supervision cost is, the more reluctant local government is to supervise the mining enterprises. From Figure 11, the more penalty local government imposes on the mining enterprises, the faster the speed of the strategy choice tending to supervise is. Meanwhile, when mining enterprises suffer the greater penalty, the probability of local government choosing to supervise will be greater. Comparing the two figures, we can find that local government's supervision cost is generally less than the penalty for not-fulfilling of mining enterprises. When $K$ is equal to or less than $C_{1}$, 


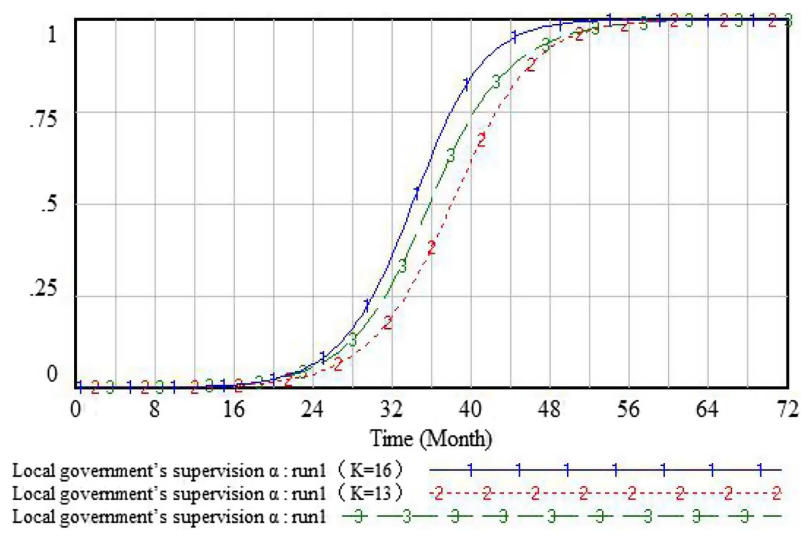

Figure 11. K's influence on local government's strategy choice.

local government is so hard to benefit from the supervision strategy that it tends to choose the non-supervision strategy. Once $K$ is greater than $C_{1}$, local government can benefit from the supervision and will choose the most advantageous strategy which is to supervise the mining enterprises.

(2) The influencing factors on local community's strategy choice.

In this situation, the initial choice of local community is not to participate and mutation evolution is carried out with a probability of 0.01 . When exogenous variables take the initial value, the strategy will reach a balance at 1 , which means, local community will ultimately choose to participate in supervision. Through dynamic simulation, we can see that the exogenous variables related to local community are: fixed payoff from participation in supervision $R_{2}$; Indirect benefit from mining enterprises' fulfilling social responsibility $P_{2}$; cost of participating in the supervision $C_{2}$; compensation for mining enterprises not fulfilling their responsibility even under local government's supervision $M_{2}$; economic and ecological losses caused by mining enterprises' failure to fulfill their social responsibility $F_{2}\left(F_{2}\right.$ includes $F_{3}$, losses caused by conflicts with mining enterprises). These variables [66] will have an impact on local community's strategy choice.

Adjusting the value of a single exogenous variable, increasing the value of $R_{2}$ and $M_{2}$, and decreasing the value of $C_{2}$ and $F_{2}$ will make local community choose the participation strategy more quickly. The change trend of the strategy choice is similar to that in Figures 10 and 11, which shows as "S-shaped growth"; and the figures are not listed separately here. When several variables' values change at the same time, local community's strategy choices are shown in Figures 12 and 13.

From Figure 12, we can see that the difference between $R_{2}$ and $C_{2}$ will have a significant impact on local community's strategy choice. When $R_{2}>C_{2}$, although the strategy will evolve from not-participating to participating, with the difference between $R_{2}$ and $C_{2}$ decreasing, the speed of evolution will gradually decrease until $R_{2}=C_{2}$, when the stable strategy of local community will become not-participating. In Figure 12, local community's strategy choice is also affected by $F_{2}$ and $M_{2}$. When local community is compensated enough for the damage, its strategy tends to participate. When its compensation is insufficient for the damage, it tends not to participate in the supervision. Thereby, in the supervision, local government should provide relevant safeguard measures and incentives to effectively encourage local community's participation.

(3) The influencing factors on mining enterprises' strategy choice.

In this case, mining enterprises initially choose not-fulfilling strategy and evolve with the probability of 0.01 , and it eventually reaches a stable equilibrium at 1 , which means, they will ultimately choose fulfilling strategy. Through dynamic simulation, it can be seen that $C_{3}$ and $K$ will have an impact on mining enterprises' strategy choice. 


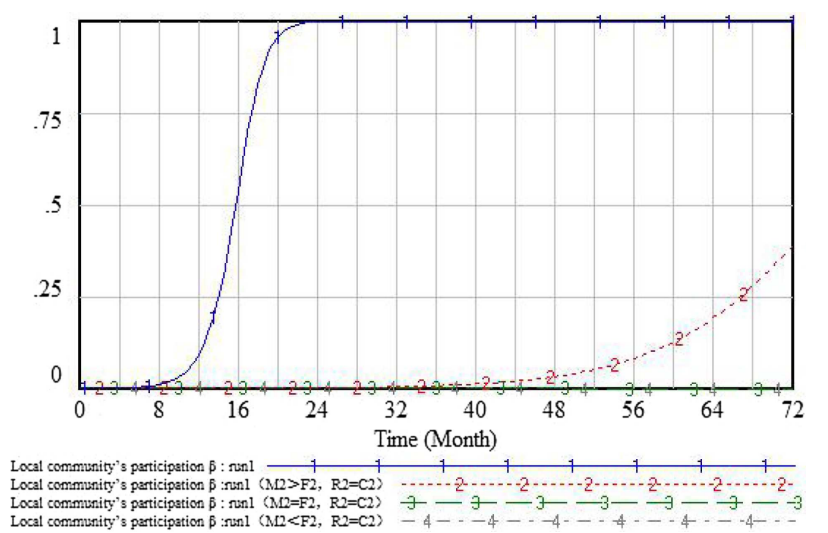

Figure 12. The four variables' influence on local community's strategy choice.

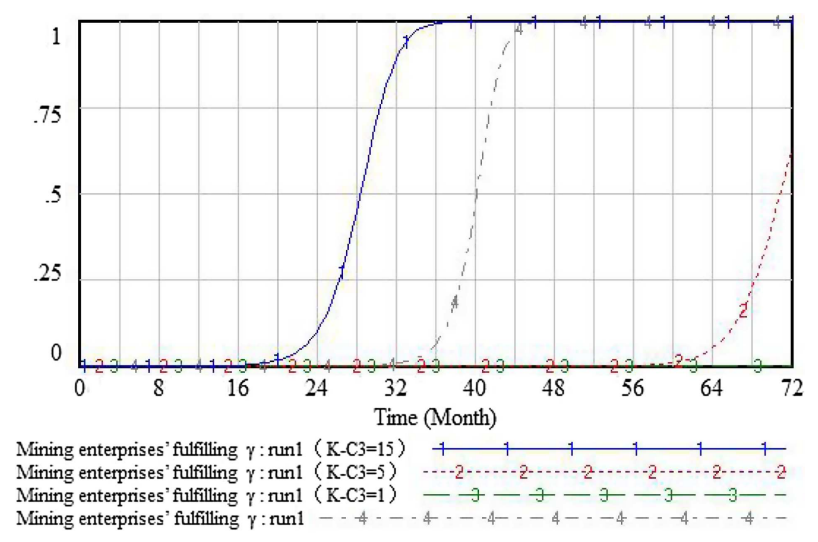

Figure 13. $C_{3}$ and $K$ 's influence on mining enterprises' strategy choice.

As can be seen from Figure 13, the greater the difference between $K$ and $C_{3}$ is, the shorter the time it takes for mining enterprises to evolve from not-fulfilling to fulfilling strategy. So we can infer that there will be a value which can make the time from the failure of the company to fulfill social responsibility to the fulfillment of social responsibility be 0 . Once the difference surpasses the specific value, mining enterprises will choose fulfilling strategy at the beginning. On the contrary, when the difference between $K$ and $C_{3}$ is getting smaller, the time it takes will be longer, and there may be another value which makes the mining company always choose not to fulfill the social responsibility. In order to shorten the time from the mining enterprise' not fulfilling the social responsibility to fulfilling the social responsibility, the difference between $K$ and $C_{3}$ can be increased, but the value of $K$ can not be continuously increased, because in the actual supervision, once the penalty of notfulfilling exceeds mining enterprise's budget, the excessive pressure will lead to enterprise's negative response. Therefore, local government should rationally formulate penalty for not-fulfilling, which can not only stimulate mining enterprises to fulfill their responsibility, but also achieve reasonable supervision. 


\section{Conclusions And Suggestion}

This paper based on evolutionary game theory studies the collaboration mechanism among local government, local community and mining enterprises, when mining enterprises fulfill their social responsibility. We draw the following conclusions through system dynamics simulation analysis.

(1) Regardless of what the three parties' initial strategies are, after continuous evolution, they will eventually reach the stable equilibrium at $(1,1,1)$ where local government supervise mining enterprises, local community actively participate in regulation and mining enterprises are voluntary to fulfil their responsibility. The participation of local community has a positive effect on promoting supervision. If local government chooses the supervision strategy at first, it will simplify and direct the evolutionary path of the parties to achieve a stable equilibrium.

(2) Local government plays a dominant role in supervision. The strategy choices of mining enterprises and local community largely depend on local government's strategy and the relationship between the size of exogenous variables is determined by local government and variables.

(3) During the supervision, even though a single exogenous variable may affect the strategy choice of the three parties, the formation of ultimate strategy results from the interaction of multiple exogenous variables. For example, the participating willingness of local community is not only influenced by the difference between the benefits of participation and the costs of participation, but also by the damage caused by the failure of mining enterprises and the difference in compensation received. The penalty imposed by local government on the failure of mining enterprises can affect the strategy choices of local government and mining enterprises at the same time. In addition, the strategy choices of both are also affected separately by supervision cost and fulfilling cost.

In order to drive the mining enterprises to fulfill their responsibilities actively, promote the parties to achieve a better game equilibrium and enhance their relative stability and sustainability in fulfilling their responsibilities, this paper puts forward the following suggestions on the basis of the above research results:

(1) To give full play of the leadership and management abilities of local government and realize the target interests of each participant, we build a tripartite interest balance mechanism. In the mechanism, we need to formulate appropriate penalty and interest safeguard measures, which can protect the interests of all parties from damage and mobilize the enthusiasm of all parties to participate in supervision.

(2) We can establish a systematic and effective local community participation system to encourage local community to participate in supervision. Local government should strengthen the openness of information and reduce the information cost of local community's participation. We should set up local community opinion and response feedback mechanism to improve the effectiveness of local community's participation and make it become an important party to evaluate the effect of fulfilling, which meets the interests of local community, let it play a role in supervising mining enterprises, and reduce the cost of local government supervision as well.

Acknowledgements. This work is financially supported by the Industrial Key Project of Key R \& D Plan of Shaanxi Province (No. 2020GY-211), and the Project of Yulin Science and Technology Plan (Name: Study on sand fixation and water conservation technology and demonstration application of ecological restoration of geological environment in mining area).

\section{REFERENCES}

[1] N. Bian and Z.H. Miao, CSR research on mining corporations from the prospective of stakeholder. Ecol. Econ. 30 (2014) $111-117$.

[2] Q.R. Cao and K. Li, Study on the influence of managerial behavior on unsafe behavior of miners. J. Manage. Sci. 24 (2011) 69-78.

[3] K. Cheng, Analysis on the Multi-population evolutionary game of social responsibility of private enterprises. Econ. Manage. 32 (2018) 62-67. 
[4] L.J. Cheng and W.Q. Zhong, Research on mechanism through which safety supervision affects miners'unsafe behaviors. J. Saf. Sci. Technol. 25 (2015) 16-22.

[5] J. Dubiński, Sustainable development of mining mineral resources. J. Sustainable Min. 12 (2013) 1-6.

[6] Y.J. Fang, W. Wei and F. Liu, Improving solar power usage with electric vehicles: analyzing a public-private partnership cooperation scheme based on evolutionary game theory. J. Cleaner Prod. 233 (2019) 1284-1297.

[7] A.J. Fogarty, Safety climate and the theory of planned behavior: towards the prediction of unsafe behavior. Accident Anal. Prev. 42 (2010) 1455-1459.

[8] B.Z. Ge, B. Wang and X.L. Dong, Source control method of acid mine wastewater from tailing pond. Chin. Min. Ind. 24 (2015) 88-93.

[9] Q.H. Gu and H.Y. Xie, Location optimization with uncertainty for industrial project using discrete block model and spatial meshing algorithm. Am. Soc. Civ. Eng. 33 (2019) 0000809.

[10] Q.H. Gu, X.X. L and S. Jiang, Hybrid genetic grey wolf algorithm for large-scale global optimization. Complexity 28 (2019) $701-719$.

[11] Q.H. Gu, S. Jiang and M.J. Lian, Health and safety situation awareness model and emergency management based on multisensor signal fusion. Spec. Sect. New Trends Brain Signal Process. Anal. 21 (2019) 958-968.

[12] X.L. Han, EAP's Application in Dealing with the Burnout of Civil Servants in China. Changchun University of Technology, China (2018).

[13] S.Y. He, J.X. Lai and L.X. Wang, A literature review on properties and applications of grouts for shield tunnel. Constr. Build. Mater. 231 (2020) 468-482.

[14] G.Q. Huang and Q.Q. Lu, Analysis of wind flow characteristics around the installation location of underground fans in mines. Chem. Miner. Process. 6 (2017) 44-50.

[15] G.Q. Huang and Q.Q. Lu, Research on the method of division of the complex ventilation system in mines and its implementation scheme. Chem. Miner. Process. 7 (2017) 50-55.

[16] X.T. Huang, T. Zhu and W.J. Duan, Comparative studies on catalytic mechanisms for natural chalcopyrite-induced Fenton oxidation: effect of chalcopyrite type. J. Hazard. Mater. 381 (2020) 120998.

[17] P. Jiang and D.W. Wang, Investment decision and analysis of metal mine mining under risk management. Friends Acc. 16 (2013) 48-50.

[18] S. Jiang, M.J. Lian and C.W. Lu, Ensemble prediction algorithm of anomaly monitoring based on big data analysis platform of open-pit mine slope. Complexity 20 (2018) 688-703.

[19] S. Jiang, C.W. Lu and S. Zhang, Prediction of ecological pressure on resource-based cities based on an RBF neural network optimized by an improved ABC algorithm. IEEE Access. 7 (2019) 47423-47436.

[20] S. Jiang, M.J. Lian and C.W. Lu, SVM-DS fusion based soft fault detection and diagnosis in solar water heaters. Energy Explor. Exploit. 37 (2019) 1125-1146.

[21] J.X. Lai and S. Mao, Investigation progresses and applications of fractional derivative model in geotechnical engineering. Math. Prob. Eng. 15 (2016) 9183296.

[22] J.X. Lai and X.L. Wang, A state-of-the-art review of sustainable energy based freeze proof technology for cold-region tunnels in China. Renewable Sustainable Energy Rev. 82 (2018) 3554-3569.

[23] J.X. Lai and X.L. Wang, Extreme deformation characteristics and countermeasures for a tunnel in difficult grounds in southern Shaanxi, China. Environ. Earth Sci. 77 (2018) 706.

[24] B. Lei and M.J. Lian, Research on measurement of metallurgy and mining enterprise informatization level. Metal Mines. 3 (2017) 131-136.

[25] N.W. Li and L.X. Niu, The structure of miners'job burnout and its questionnaire compilation. J. Southwest Univ. 35 (2009) $133-137$.

[26] W. Li and S. Yang, Simulation analysis on unsafe behavior of miners in perspective of behavioral economics. J. Saf. Sci. Technol. 14 (2018) 18-23.

[27] M.L. Li, Q. Zhang and Z.X. Zou, Evolutionary game analysis of social responsibility in the food supply chain enterprises. Oper. Manage. 26 (2017) 34-44.

[28] P.L. Li, Y.Q. Lu and J.X. Lai, A comparative study of protective schemes for shield tunneling adjacent to pile groups. Adv. Civ. Eng. 12 (2020) 1874137.

[29] Q. Liu, X.B. Feng and Y.L. He, Three-dimensional multiple-relaxation-time lattice boltzmann models for single-phase and solid-liquid phase-change heat transfer in porous media at the REV scale. Appl. Therm. Eng. 152 (2019) 319-337.

[30] M.J. Lian, D.Y. Yuan and Z.L. Wang, Establishment and application of RHO safety production management system in metallurgical mine. Min. Res. Dev. 38 (2018) 139-142.

[31] Z.D. Liang, SEM-based study on effects of organizational and environmental factors on workers' unsafe behavior. J. Saf. Sci. Technol. 22 (2012) 16-22.

[32] C. Liu, Z.Y. Lv and C. Zhu, Study on calculation method of long term deformation of RAC beam based on creep adjustment coefficient. KSCE J. Civ. Eng. 23 (2019) 260-267.

[33] Q. Liu, X.B. Feng and Y.L. He, Multiple-relaxation-time lattice boltzmann model for simulating axisymmetric thermal flows in porous media. Int. J. Heat Mass Transfer. 137 (2019) 1301-1311.

[34] T. Liu, Y.J. Zhong and Z.H. Feng, New construction technology of a shallow tunnel in Boulder-Cobble mixed grounds. Adv. Civ. Eng. 14 (2020) 91986253. 
[35] T. Liu, Y.J. Zhong and Z.L. Han, Deformation characteristics and its countermeasures for a tunnel in difficult geological environment in NW China. Adv. Civ. Eng. 12 (2020) 5137279.

[36] T. Long, X.T. Huang and W. Xiao, The effect of surface charge on the separation of pyrite from serpentine by flotation. Minerals 9 (2019) 629.

[37] T. Long, W. Xiao and W. Yang, The effect of molecular assembly between collectors and inhibitors on the flotation of pyrite and talc. R. Soc. Open Sci. 6 (2019) 191133.

[38] C.W. Lu, Q.Q. Ma and X.F. Zhang, Simulation and optimization of mine supply and demand chain based on Petri net under delayed manufacturing. Chin. Min. Ind. 28 (2019) 72-79.

[39] B. Ma, M.J. Lian and C.W. Lu, Conceptual model of digital mine information integration. Metal Mines 7 (2014) $135-140$.

[40] G.H. Ma, H. Qun and S.Q. Zhu, Research on the ways to overcome college counselors' burnout guided by social cognitive career theory: taking Hunan University of Traditional Chinese Medicine as an Example. Mod. Edu. 5 (2018) $295-297$.

[41] L. Ma, C.W. Lu and Q.H. Gu, Industrial mining production planning model and optimization algorithm for polymetallic mines. Ind. Eng. Manage. 23 (2018) 50-56+64.

[42] D. Ma, G.B. Shi and B. Li, Optimization of space spacing and dynamic effect analysis of a roadway in a mine. Metal Mine. 11 (2019) 27-34.

[43] A. Marifran, qualitative comparison of susceptibility and behavior in recreational and occupational risk environments: implications for promoting health and safety. J. Health Commun. 21 (2016) 705-713.

[44] H.J. Mi, C.W. Lu and Z.D. Feng, Research on MapX-based mining vehicle positioning simulation technology. Metal Mines 4 (2012) 124-127.

[45] X.X. Nie and G.D. Zhang, Reliability Research of underground mine emergency avoidance system based on entropy method and catastrophe theory. Gold Sci. Technol. 24 (2016) 72-77.

[46] X.X. Nie, S.S. Feng and S.D. Zhang, Simulation study on the dynamic ventilation control of single head roadway in high-altitude mine based on thermal comfort. Adv. Civ. Eng. 12 (2019) 2973504.

[47] X.X. Nie, W.J. Zhai and C.W. Lu, Price prediction of molybdenum concentrate based on grey-markov model. J. Environ. Prot. Ecol. 19 (2018) 1955-1963.

[48] X.X. Nie, X.B. Wei and X.C. Li, Heat treatment and ventilation optimization in a deep mine. Adv. Civ. Eng. 12 (2018) 1529490.

[49] X.X. Nie, C.R. Bai and J.J. Zhang, Simulation research on the effectiveness of a multi-agent mine safety supervision system. Math. Prob. Eng. 13 (2020) 8457124.

[50] X.X. Nie, Q. Gan and C.R. Bai, The developing sequences of continuous mining for thin ore clusters based on collaborative mining theory. Adv. Civ. Eng. 10 (2020) 2068098.

[51] J.L. Qiu and H.Q. Liu, Investigating the long-term settlement of a tunnel built over improved loessial foundation soil using jet grouting technique. J. Perform. Constr. Facil. 5 (2018) 04018066.

[52] J.L. Qiu, X.L. Wang and J.X. Lai, Response characteristics and preventions for seismic subsidence of loess in Northwest China. Nat. Hazards 92 (2018) 1909-1935.

[53] J.L. Qiu, Y.W. Qin and J.X. Lai, Structural response of the metro tunnel under local dynamic water environment in loess strata. Geofluids. 16 (2019) 8541959.

[54] J.L. Qiu, T. Yang and X.L. Wang, Review of the flame retardancy on highway tunnel asphalt pavement. Constr. Build. Mater. 195 (2019) 468-482.

[55] B.L. Shao and Q. Wu, Reliability analysis of mine underground drainage system. Metal Mine. 7 (2013) 159-161+165.

[56] M.K. Sohrabi and H. Azgomi, Evolutionary game theory approach to materialized view selection in data warehouses. Knowl.Based Syst. 163 (2019) 558-571.

[57] L.H. Sun, Research on the burnout of secretaries in party and government offices of universities and colleges - Taking Zhejiang University and nanjing normal university as examples. Secretary. 6 (2018) 36-47.

[58] H. Sun, Q.P. Wang and P. Zhang, Spatiotemporal characteristics of tunnel traffic accidents in China from 2001 to present. Adv. Civ. Eng. 16 (2019) 4536414.

[59] B. Wang and X.L. Dong, Experimental study on influence of mine leachate on permeability characteristics of geosynthetic clay liner under different effective stresses. Rock Soil Mech. 38 (2017) 1350-1358.

[60] G.H. Wang and N. Li, Selection game model of air service provider based on corporate social responsibility. J. Traffic Transp. Eng. 15 (2015) 90-99.

[61] S.Q. Wang and J.L. Qiu, Research on circulation ventilation technology of parallel double-hole long gas tunnel. Highway Transp. Technol. 11 (2015) 230-232+309.

[62] Q.P. Wang and H. Sun, Traffic structure optimization in historic districts based on green transportation and sustainable development concept. Adv. Cvil Eng. 18 (2019) 9196263.

[63] P. Wang and J.S. Zhou, Research on social responsibility of chinese mining enterprises from the perspective of low carbon economy. Chin. Population Res. Environ. 22 (2012) 46-49.

[64] Z.L. Wang, Q.H. Gu and H.J. Wang, Sinopec Fuquan Mining's "five in one" green mine construction model and practice. Chin. Min. Ind. 27 (2018) 72-76.

[65] X. Wei, Y.L. Zhao and J. Yang, Effect of sodium oleate on the adsorption morphology and mechanism of nanobubbles on the mica surface. Langmuir 35 (2019) 9239-9245.

[66] S.S. Wu, J.P. Guo and G.B. Shi, Laboratory-based investigation into stress corrosion cracking of cable bolts. Materials 12 (2019) 2146. 
[67] X.C. Xie, Z.H. Yang and G.G. Xu, Human safety analysis of mine safety based on improved HFACS and SPA. J. Saf. Environ. 15 (2015) 37-42.

[68] X.C. Xie, Z.H. Yang and G.G. Xu, Research on safety management level of mining enterprises based on SMART principle and D-S Theory. Ch. Saf. Sci. Technol. 11 (2015) 90-94.

[69] S.W. Zhan and S.Y. Li, Study on the impact of mining on the welfare of local villagers. J. Xi'an Univ. Archit. Technol. 46 (2014) 270-275.

[70] Y.M. Zhang, Y.L. Wang and S.J. Zhang, Analysis of social responsibility of coal enterprises in China based on game theory. Min. Metall. Eng. 33 (2013) 139-144.

[71] H. Zhang, J.N. Gu and G.Z. Lu, Dynamic game analysis of host government's supervision of multinational corporations' social responsibility practice. Dong Yue Tribune 35 (2014) 152-157.

[72] Y.W. Zhang, J.X. Lai and J.L. Qiu, Test and analysis of frost heave effect of tunnels in cold areas. J. Transp. Eng. 18 (2018) $64-73$.

[73] S.B. Zhang, S.Y. He and J.L. Qiu, Displacement characteristics of a urban tunnel in silty soil by shallow tunnelling method. Adv. Civ. Eng. 15 (2020) 3975745.

[74] Y. Zuo and Y.Z. Zhang, From feed-in tariff to renewable portfolio standards: an evolutionary game theory perspective. J. Cleaner Prod. 213 (2019) 1274-1289. 